\title{
Cigarette smoking and colorectal cancer mortality among 602,242 Norwegian males and females
}

\author{
Ranjan Parajuli' \\ Eivind Bjerkaas' \\ Aage Tverdal ${ }^{2}$ \\ Loïc Le Marchand ${ }^{3}$ \\ Elisabete Weiderpass ${ }^{1,4-6}$ \\ Inger T Gram ${ }^{1,7}$ \\ 'Department of Community Medicine, \\ Faculty of Health Sciences UiT, \\ The Arctic University of Norway, \\ Tromsø, Norway; ${ }^{2}$ Division of \\ Epidemiology, Department of \\ Pharmacoepidemiology, Norwegian \\ Institute of Public Health, Oslo, \\ Norway; ${ }^{3}$ Epidemiology Program, \\ University of Hawaii Cancer Center, \\ Honolulu, HI, USA; ${ }^{4}$ Department \\ of Medical Epidemiology and \\ Biostatistics, Karolinska Institutet, \\ Stockholm, Sweden; ${ }^{5}$ Department \\ of Genetic Epidemiology, Samfundet \\ Folkhälsan, Helsinki, Finland; \\ ${ }^{6}$ Department of Research, Cancer \\ Registry of Norway, Oslo, Norway; \\ ${ }^{7}$ Norwegian Centre for Integrated \\ Care and Telemedicine, University \\ Hospital of North Norway, Tromsø, \\ Norway
}

This article was published in the following Dove Press journal:

Clinical Epidemiology

7 April 2014

Number of times this article has been viewed
Background: Colorectal cancer (CRC) is one of the main cancer types, with high incidence and mortality in Norway. We examined the association between different measures of smoking exposure and CRC mortality overall and by subsite in a large Norwegian cohort.

Methods: We followed 602,242 participants from four Norwegian health surveys, aged 19-67 years at enrollment between 1972 and 2003 by linkage to the national registries through December 2007. We used Cox proportional hazard models to estimate hazard ratios (HRs) and 95\% confidence intervals (CIs) by smoking categories for different CRC endpoints.

Results: During a mean follow-up of 14 years, 2,333 Norwegian males and females died of CRC (60\% men). Male and female ever smokers had a 20\% (HR 1.23, CI 1.08-1.40 and HR $1.22,95 \%$ CI 1.06-1.40, respectively) increased risk of death from CRC compared with sex-specific never smokers. For proximal colon cancer mortality, female ever smokers had a 50\% (HR 1.49, 95\% CI 1.20-1.87) increased risk compared with female never smokers. The increased risk of rectal cancer mortality was about 40\% higher for male ever smokers (HR 1.43, 95\% CI 1.14-1.81) compared with male never smokers. A test for heterogeneity by sex showed an increased risk of rectal cancer mortality among men which was significant for former smokers (Wald $\chi^{2}=0.02$ ) and an increased risk of proximal colon cancer mortality among women which was significant for ever and former smokers (Wald $\chi^{2}=0.02$ and $\chi^{2}=0.04$, respectively).

Conclusion: Smoking is associated with increased CRC mortality in both sexes. The risk of rectal and proximal colon cancer mortality was most pronounced among male and female smokers respectively.

Keywords: colorectal cancer, mortality, cigarette smoking, sex, cohort study, Norway

\section{Introduction}

Colorectal cancer (CRC) accounts for $8 \%$ of all cancer deaths, making it the fourth most common cause of death from cancer worldwide. ${ }^{1} \mathrm{CRC}$ is the second most common cause of cancer death in Europe. ${ }^{2}$ Worldwide, mortality rates are lower in women than in men except in the Caribbean region. ${ }^{1}$ In Norway, the incidence of CRC is the second highest after breast cancer among women and third highest after lung and prostate cancer in men. The 5-year incidence of CRC was 43 for men and 35 for women per 100,000 person-years in 2007 to 2011, which is adjusted to the world population. However, the mortality rate for CRC ranks third among men after lung and prostate cancer and second among women after lung cancer. ${ }^{3}$

Cigarette smoking is the major preventable and modifiable cause of death worldwide. ${ }^{4}$ The World Health Organization has reported that almost 100 million deaths were caused by cigarette smoking in the 20 th century, and if this trend
Correspondence: Inger T Gram Department of Community Medicine UiT, The Arctic University of Norway, N-9037 Tromsø, Norway

Tel +47 77645360

Fax +47 7764 4831

Email inger.gram@uit.no 
continues, another one billion smoking-related deaths are expected in the 21 st century. ${ }^{5}$ Presently, smoking is attributed to approximately 6 million premature deaths annually worldwide. If prevention measures are not implemented soon, the death toll is expected to reach 8 million per year by 2030 . The casual association between cigarette smoking and CRC was recently re-evaluated by an expert group from the International Agency for Research on Cancer, ${ }^{6}$ with the conclusion that smoking is a risk factor for both colon and rectal cancer. It has been proposed that about $12 \%$ of CRC deaths are attributable to smoking. ${ }^{7,8}$

The prevalence of smoking in Norway for men was about $52 \%$ in 1973 ; by 2007 , there had been more than a $50 \%$ reduction to $24 \%$. The proportion of women smokers remained at around 30\% from 1973 to 2002. After 2002, there was a substantial decline in women who smoked daily, and the prevalence of women smokers was similar to that of men by 2007. ${ }^{9-11}$ We have previously reported that the increased risk of colon cancer due to cigarette smoking may be greater in women than in men. ${ }^{12}$

The main purpose of this study was to prospectively examine the association between cigarette smoking and CRC mortality in a large Norwegian cohort. We also wanted to investigate if the association differed by sex.

\section{Materials and methods Study population}

Our study included 652,792 subjects (49\% men) who participated in several Norwegian health surveys (the Oslo study I, the Norwegian Counties study, the 40 years cohort, and the Cohort of Norway [CONOR]). These surveys were conducted between 1972 and 2003, and were merged into one database which constitutes the basis of the present study. Our study was approved by the Regional Committee for Medical Research Ethics South-East Norway. Detailed information on the study population can be found elsewhere. ${ }^{12,13}$

\section{Exposure information}

All surveys had a baseline questionnaire that included a detailed assessment of smoking habits, physical activity, and other lifestyle factors. The questionnaires included questions on current and former smoking habits, smoking duration, and average number of cigarettes smoked per day; some also asked about age at smoking initiation. Current smokers were defined as those who were daily smokers, and former smokers were classified according to years since quitting smoking, or if they answered that they had smoked previously, but were not smokers at the time of enrollment.
Current and former smokers were also classified as ever smokers, and categorized according to the following factors at enrollment: age at smoking initiation, average number of cigarettes smoked per day, smoking duration in years, and number of pack-years (ie, number of cigarettes smoked per day, divided by 20, multiplied by the duration of smoking, in years). Only the CONOR study asked about the age at smoking initiation. In other surveys, we calculated age at smoking initiation for both current (ie, age at enrollment minus duration of smoking, in years) and for former smokers (age at quitting smoking minus duration of smoking, in years). Participants who were neither current nor former smokers were classified as never smokers. Body mass index was calculated as weight in kilograms divided by the square of height, in meters. The participants were categorized into three groups based on the level of physical activity reported in the baseline questionnaires: a sedentary group (reading, watching television, and sedentary activity $<4$ hours a week); a moderate group (walking, bicycling, or similar activities $\geq 4$ hours a week); and a heavy physical activity group (heavy exercise and daily competitive sports, and light sports, or heavy gardening $\geq 4$ hours a week). Information regarding duration of education was obtained from Statistics Norway and participants were assigned to one of the three categories by duration of education, ie, less than 10 years, 10-12 years, and 13 or more years.

\section{Follow-up and endpoints}

The participants were linked to the Cancer Registry of Norway, the Norwegian Cause of Death Registry, and the Central Population Register. The unique 11-digit personal identification number was utilized to identify all cancer deaths and emigration respectively. The national registries contain correct and detailed information regarding cancer incidence and mortality. ${ }^{14} \mathrm{CRC}$ mortality was classified according to the ninth and tenth revisions of the International Statistical Classification of Diseases. Follow-up ended at the time of death from primary CRC cancer, death from any other cancer (except basal cell carcinoma of the skin), emigration, death from other causes, or December 31, 2007, whichever occurred first.

We excluded 11,476 subjects who were diagnosed with any invasive cancer prior to the start of the study, and 1,009 subjects who emigrated or died before the start of follow-up. We further excluded 6,299 subjects with insufficient information on smoking history. Finally, we excluded those with missing information on body mass index $(n=5,107)$, physical activity $(n=8,210)$, or education $(n=18,449)$, leaving 602,242 (49.7\% men) in the analytical cohort. 


\section{Statistical analysis}

We used Student's $t$-test and $\chi^{2}$ test to investigate the distribution of selected characteristics between current and never smokers. All analyses were conducted separately by sex. The Cox proportional hazards model was used with age as the underlying time scale to estimate multivariate-adjusted hazard ratios (HRs) with 95\% confidence intervals (CIs) for the associations between different measures of smoking exposure and colorectal, colon, and rectal cancer deaths with never smokers as the reference group. Entry time was defined as age at enrollment and exit time was age at death, emigration, or end of follow-up (December 31, 2007), whichever occurred first. The ever smoking variables were analyzed separately for males and females. These were: age at smoking initiation in years $(\leq 19,20-24, \geq 25)$, numbers of cigarettes smoked per day $(1-9,10-19, \geq 20)$, smoking duration in years $(1-19,20-29$, $\geq 30)$, and number of pack-years $(0-9,10-19, \geq 20)$.

Possible confounders included in the final models, selected a priori, were age (continuous), level of physical activity (sedentary, moderate, heavy), and body mass index (continuous) at enrollment, and years of education ( $<10$ years, $10-12$ years, $\geq 13$ years). Tests for linear trends were obtained by creating an ordinal exposure variable with equally spaced scores and including it in the models, and we performed the trend tests with never smokers included. We reanalyzed the data excluding the 8,151 (99\% men) subjects who reported smoking only cigars or a pipe. We had information on alcohol consumption for $37 \%(n=221,748)$ of participants. We undertook sensitivity analyses by sex for the main outcomes based on this population ( $49 \%$ men) enrolled after 1995 . Heterogeneity by sex with regard to the effect of smoking and risk of CRC mortality was tested with the Wald $\chi^{2}$. Two-sided $P$-values $<0.05$ were considered to be statistically significant. All analyses were conducted using STATA version 12.0 (Stata Corp, College Station, TX, USA).

\section{Results}

During a mean 14 years of follow-up and 8.6 million personyears of observation, there were 2,333 CRC deaths $(60 \%$ men) of which 1,607 were from colon cancer ( $57 \%$ men) and 726 from rectal cancer $(67 \%$ men). Table 1 shows that the 40 years cohort was the largest study, contributing $64 \%$ of participants and $37 \%$ of CRC deaths. The mean age at enrollment varied from 40 years in the Norwegian counties study to 48 years in the CONOR study. About $63 \%$ of all the participants were ever smokers at enrollment. For both sexes and in all surveys, current smokers had a shorter duration of education, were less physically active, and had a lower body mass index compared with never smokers (all $P$-values $<0.0001$, data not shown).

Table 2 shows that male ever smokers had a $23 \%$ increased risk of dying from CRC (HR 1.23, CI 1.08-1.40) and male ever smokers included in the Norwegian counties study had an approximately $40 \%$ increased risk of CRC

Table I Selected characteristics of the study population, stratified by cohort, among 602,242 Norwegian males and females (1972-2003) at enrollment

\begin{tabular}{|c|c|c|c|c|c|}
\hline Characteristics & $\begin{array}{l}\text { Oslo study }\left.\right|^{a} \\
(1972-1973)^{33-36}\end{array}$ & $\begin{array}{l}\text { Norwegian } \\
\text { counties study } \\
(1974-1987)^{36-39}\end{array}$ & $\begin{array}{l}40 \text { years cohort } \\
(1985-1999)^{36,40,41}\end{array}$ & $\begin{array}{l}\text { CONOR study } \\
(1994-2003)^{36,42,43}\end{array}$ & $\begin{array}{l}\text { All } \\
(1972-2003)\end{array}$ \\
\hline Subjects & 16,946 & 83,486 & 384,767 & 117,043 & 602,242 \\
\hline Person-years of follow-up & 475,834 & $2,|3|, 87 \mid$ & $4,985,334$ & 968,293 & $8,561,332$ \\
\hline Age (years, mean, SD) & $45 \pm 6$ & $40 \pm 7$ & $43 \pm 5$ & $48 \pm 14$ & $44 \pm 8$ \\
\hline $\begin{array}{l}\text { Age at CRC diagnosis among cases } \\
\text { (mean, SD) }\end{array}$ & $68 \pm 8$ & $63 \pm 9$ & $57 \pm 10$ & $68 \pm 12$ & $62 \pm 11$ \\
\hline Age at death, all causes ${ }^{\mathrm{b}}$ (mean, SD) & $70 \pm 8$ & $64 \pm 9$ & $61 \pm 13$ & $76 \pm 13$ & $66 \pm 12$ \\
\hline Age at CRC deaths ${ }^{\mathrm{b}}$ (mean, SD) & $70 \pm 7$ & $64 \pm 8$ & $60 \pm 12$ & $73 \pm 12$ & $65 \pm 11$ \\
\hline CRC deaths $(n)$ & 388 & 723 & 860 & 362 & 2,333 \\
\hline Colon cancer deaths $(\mathrm{n})$ & 238 & 468 & 624 & 277 & 1,607 \\
\hline Rectal cancer deaths (n) & 150 & 255 & 236 & 85 & 726 \\
\hline Year of birth, median (IQR) & $1928(1925-1931)$ & $1938(1932-1944)$ & $1950(1948-1954)$ & $1950(194 \mid-1960)$ & $1950(1944-1954)$ \\
\hline Follow-up years, median (IQR) & $32(24-33)$ & $29(20-30)$ & $13(10-16)$ & $9(6-10)$ & $13(9-17)$ \\
\hline$\geq 13$ years of education ${ }^{\mathrm{b}}(\%)$ & 24 & 13 & 24 & 21 & 22 \\
\hline Body mass index $\left(\mathrm{kg} / \mathrm{m}^{2}\right.$, mean, $\left.S \mathrm{~S}\right)$ & $25 \pm 3$ & $25 \pm 4$ & $25 \pm 4$ & $26 \pm 4$ & $25 \pm 4$ \\
\hline Level of physical activity, heavyc (\%) & 20 & 21 & 28 & 33 & 28 \\
\hline \multicolumn{6}{|l|}{ Smoking status } \\
\hline Never smokers (\%) & 21 & 36 & 36 & 41 & 37 \\
\hline Ever smokers (\%) & 79 & 64 & 64 & 59 & 63 \\
\hline
\end{tabular}

Notes: ancluded only men; b not at enrollment; cheavy physical activity, ie, light sports or heavy gardening $\geq 4$ hours per week, heavy exercise, or daily competitive sports. Abbreviations: CRC, colorectal cancer; SD, standard deviation; IQR, interquartile range. 
death (HR 1.46, 95\% CI 1.12-1.89). The risk estimates for cigarette smoking and CRC death in male ever smokers did not reveal any significant results for other surveys compared with study-specific male never smokers. By survey, the trend test was significant for different smoking exposures and CRC mortality in men (except for age at smoking initiation) only in the Norwegian counties study.

Table 3 shows that women who were ever smokers had a $22 \%$ increased risk of death from CRC (HR 1.22, 95\% CI 1.06-1.40) when compared with female never smokers. Female ever smokers included in the Norwegian counties study had a significant $30 \%$ increased risk of death from CRC (HR 1.32, 95\% CI 1.05-1.64). As in men, the risk estimates for cigarette smoking and $\mathrm{CRC}$ death in female ever smokers were not significant for other surveys compared with studyspecific female never smokers. By survey, the trend test was significant for different smoking exposure and CRC mortality only for women in the Norwegian counties study.

Table 4 shows that the risk of death from rectal cancer was about $40 \%$ higher for male ever smokers (HR 1.43, 95\% CI 1.14-1.81) compared with male never smokers. The risk estimates for smoking and colon cancer mortality and by location did not reveal any significant results among male ever smokers compared with male never smokers. The trend tests across different smoking exposure categories including never smokers as the reference group for age at smoking initiation, numbers of cigarettes smoked per day, numbers of years of smoking, and number of pack-years all yielded significant results for rectal cancer mortality among men $(P<0.05$, Table 4).

Table 5 shows that female ever smokers had a $26 \%$ increased risk of death from colon cancer (HR 1.26, 95\% CI 1.08-1.48) when compared with female never smokers. Female ever smokers had an almost 50\% increased risk of death from proximal colon cancer (HR 1.49, 95\% CI 1.20-1.87). The risk estimates for female ever smokers were not significant for distal colon cancer or rectal cancer deaths when compared with female never smokers. The trend tests across different smoking exposure categories including never smokers as the reference group for age at smoking initiation, numbers of cigarettes smoked per day, numbers of years of smoking, and number of pack-years all yielded significant results for colon cancer and proximal colon cancer mortality among women $(P<0.05$, Table 5$)$.

These estimates did not differ materially when we excluded only cigar and pipe smokers from the analyses (data not shown). In the sensitivity analyses, the risk estimates of CRC mortality for ever smokers decreased among men
(HR 0.84, 95\% CI 0.60-1.18) and stayed basically the same although were no longer significant among women (HR 1.25, 95\% CI $0.89-1.74)$. Altogether, $86 \%$ of total CRC mortality cases and $78 \%$ of all follow-up were lost when we carried out analyses only for participants with information on alcohol use (data not shown).

A test for heterogeneity by sex was also significant for former smoking and risk of rectal cancer (Wald $\chi^{2}$, $P=0.02$ ), with a pronounced risk in men. Further, this test for heterogeneity by sex was statistically significant, showing increased risk among former, and ever smoking women and risk of proximal colon cancer mortality. The Wald test for heterogeneity was borderline significant for current smokers (Wald $\chi^{2}, P=0.054$ ).

\section{Discussion}

Our study shows that both male and female ever smokers have an increased risk of CRC mortality. There was a significantly increased risk of mortality from rectal cancer among male smokers and a significantly increased risk of mortality from colon cancer (mainly of the proximal colon) in female smokers. The increased mortality risk for CRC overall was somewhat more pronounced for current smokers than for former smokers in both males and females.

Our study is a large, nationwide, prospective cohort study with virtually complete follow-up, and contains a large proportion of male and female ever smokers. Similarly, the longer follow-up period gives us more stable risk estimates. Smoking history was accessed at enrollment, which minimizes recall bias. We also consider it to be a strength that we focused our analyses on comparisons between ever smokers and never smokers. We have previously reported an increased incidence of colon and rectal cancer among males and females who were ever smokers from the same cohort. ${ }^{12}$

The study has several limitations. The information on smoking habits was only available at baseline and not during follow-up. Further, around 10\% of Norwegian males and females are occasional smokers, ${ }^{10}$ and we lacked information on passive smoking. Ever smokers have an increased risk of dying from other smoking-related diseases ${ }^{15,16}$ during follow-up due to competing risks for mortality. This could have decreased the impact of smoking and CRC mortality more among ever smokers compared with never smokers. Those who were occasional or passive smokers in our study are most likely included in the reference group, ie, the never smoker group, which might have biased our results by decreasing the risk estimates. We lacked information on alcohol consumption for the majority of our study participants, and alcohol is 


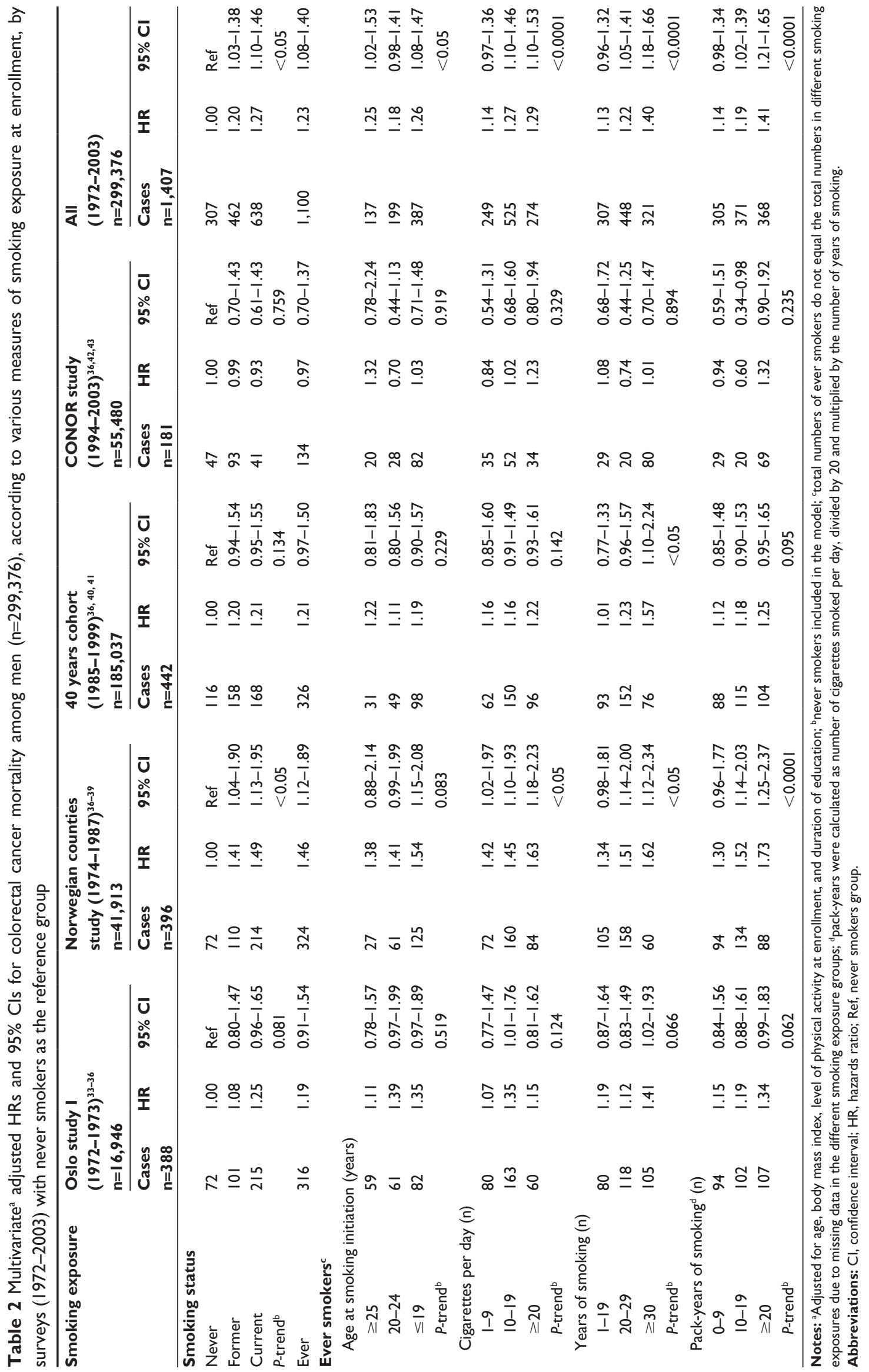


Table 3 Multivariate ${ }^{\mathrm{a}}$ adjusted $\mathrm{HRs}$ and $95 \% \mathrm{Cls}$ for colorectal cancer mortality among women ( $\left.\mathrm{n}=302,866\right)$, according to various measures of smoking exposure at enrollment, by surveys (1974-2003) with never smokers as the reference group

\begin{tabular}{|c|c|c|c|c|c|c|c|c|c|c|c|c|}
\hline \multirow[t]{2}{*}{ Smoking exposure } & \multicolumn{3}{|c|}{$\begin{array}{l}\text { Norwegian counties } \\
\text { study }(1974-1987)^{36-39} \\
\mathrm{n}=41,573\end{array}$} & \multicolumn{3}{|c|}{$\begin{array}{l}40 \text { years cohort } \\
(1985-1999)^{36,40,41} \\
n=199,730\end{array}$} & \multicolumn{3}{|c|}{$\begin{array}{l}\text { CONOR study } \\
(1994-2003)^{36,42,43} \\
n=61,563\end{array}$} & \multicolumn{3}{|c|}{$\begin{array}{l}\text { All }(1972-2003) \\
n=302,866\end{array}$} \\
\hline & $\begin{array}{l}\text { Cases } \\
\mathrm{n}=327\end{array}$ & HR & $95 \% \mathrm{Cl}$ & $\begin{array}{l}\text { Cases } \\
n=418\end{array}$ & HR & $95 \% \mathrm{Cl}$ & $\begin{array}{l}\text { Cases } \\
n=|8|\end{array}$ & HR & $95 \% \mathrm{Cl}$ & $\begin{array}{l}\text { Cases } \\
\mathrm{n}=926\end{array}$ & HR & $95 \% \mathrm{Cl}$ \\
\hline \multicolumn{13}{|l|}{ Smoking status } \\
\hline Never & 147 & 1.00 & Ref & 172 & 1.00 & Ref & 98 & 1.00 & Ref & 417 & 1.00 & Ref \\
\hline Former & 44 & 1.17 & $0.84-1.64$ & 77 & 1.05 & $0.80-1.38$ & 41 & 1.01 & $0.70-1.47$ & 162 & 1.08 & $0.90-1.30$ \\
\hline Current & 136 & 1.38 & I.08-1.75 & 169 & 1.30 & $1.03-1.63$ & 42 & 1.12 & $0.76-1.65$ & 347 & 1.30 & $1.12-1.52$ \\
\hline$P$-trend ${ }^{b}$ & & & $<0.05$ & & & $<0.05$ & & & 0.605 & & & $<0.05$ \\
\hline Ever & 180 & 1.32 & $1.05-1.64$ & 246 & 1.20 & $0.98-1.47$ & 83 & 1.06 & $0.78-1.44$ & 509 & 1.22 & $1.06-1.40$ \\
\hline \multicolumn{13}{|l|}{ Ever smokers ${ }^{c}$} \\
\hline \multicolumn{13}{|c|}{ Age at smoking initiation (years) } \\
\hline$\geq 25$ & 51 & 1.22 & $0.89-1.69$ & 48 & 1.32 & $0.96-1.82$ & 29 & 1.19 & $0.78-1.81$ & 128 & 1.25 & $1.02-1.52$ \\
\hline $20-24$ & 53 & 1.63 & $1.18-2.24$ & 62 & 1.32 & $0.97-1.80$ & 18 & 0.83 & $0.50-1.39$ & 133 & 1.31 & $|.07-1.6|$ \\
\hline$\leq 19$ & 32 & 1.31 & $0.88-1.96$ & 68 & $\mathrm{I} .14$ & $0.83-1.55$ & 31 & 1.09 & $0.69-1.72$ & 131 & 1.20 & $0.97-1.48$ \\
\hline$P$-trend ${ }^{b}$ & & & $<0.05$ & & & $<0.05$ & & & 0.673 & & & $<0.05$ \\
\hline \multicolumn{13}{|l|}{ Cigarettes per day (n) } \\
\hline $1-9$ & 82 & 1.27 & $0.97-1.67$ & 70 & 1.09 & $0.82-1.44$ & 32 & 0.82 & $0.54-1.23$ & 184 & 1.10 & $0.92-1.31$ \\
\hline $10-19$ & 80 & 1.30 & $0.99-1.72$ & 137 & 1.28 & $1.01-1.63$ & 41 & 1.40 & $0.95-2.07$ & 258 & 1.31 & $1.12-1.55$ \\
\hline$\geq 20$ & 18 & 1.68 & $1.03-2.75$ & 38 & 1.20 & $0.84-1.73$ & 6 & 1.01 & $0.44-2.34$ & 62 & 1.29 & $0.99-2.70$ \\
\hline$P$-trend ${ }^{b}$ & & & $<0.05$ & & & 0.061 & & & 0.278 & & & $<0.05$ \\
\hline \multicolumn{13}{|l|}{ Years of smoking $(n)$} \\
\hline $1-19$ & 94 & 1.21 & $0.93-1.58$ & 110 & 1.24 & $0.97-1.60$ & 25 & 1.11 & $0.70-1.76$ & 229 & 1.21 & $1.02-1.43$ \\
\hline $20-29$ & 79 & 1.47 & $1.10-1.93$ & 115 & 1.13 & $0.87-1.46$ & 23 & 1.17 & $0.72-1.89$ & 217 & 1.27 & $|.07-| .5 \mid$ \\
\hline$\geq 30$ & 7 & 1.38 & $0.64-2.98$ & 20 & 1.31 & $0.80-2.12$ & 29 & 0.94 & $0.6 \mathrm{I}-\mathrm{I} .44$ & 56 & 1.11 & $0.83-1.48$ \\
\hline$P$-trend ${ }^{b}$ & & & $<0.05$ & & & 0.168 & & & 0.970 & & & $<0.05$ \\
\hline \multicolumn{13}{|c|}{ Pack-years of smoking ${ }^{d}(n)$} \\
\hline $0-9$ & 105 & 1.21 & $0.94-1.56$ & 98 & 1.06 & $0.82-1.36$ & 31 & 0.95 & $0.63-1.44$ & 234 & 1.09 & $0.93-1.29$ \\
\hline $10-19$ & 62 & 1.52 & $1.12-2.05$ & 103 & 1.32 & I.0I-I.7I & 28 & 1.20 & $0.77-1.87$ & 193 & 1.38 & $1.15-1.65$ \\
\hline$\geq 20$ & 13 & 1.49 & $0.84-2.64$ & 44 & $1.4 \mathrm{I}$ & $1.00-1.98$ & 16 & 0.98 & $0.57-1.68$ & 73 & 1.32 & $1.03-1.70$ \\
\hline$P$-trend ${ }^{b}$ & & & $<0.05$ & & & $<0.05$ & & & 0.749 & & & $<0.000$ I \\
\hline
\end{tabular}

Notes: ${ }^{a}$ Adjusted for age, body mass index, level of physical activity at enrollment, and duration of education; ${ }^{b}$ never smokers included in the model; 'total numbers of ever smokers do not equal the total numbers in different smoking exposures due to missing data in different smoking exposure groups; ${ }^{\mathrm{d}}$ pack-years were calculated as number of cigarettes smoked per day, divided by 20 and multiplied by the number of years of smoking.

Abbreviations: $\mathrm{Cl}$, confidence interval; $\mathrm{HR}$, hazards ratio; Ref, never smokers group.

an established risk factor for CRC. ${ }^{17}$ Alcohol consumption in Norway is higher among men than women, ${ }^{18}$ and lack of adjustment for alcohol consumption could have inflated our risk estimations, especially for men. Interpretation of our subcohort findings indicated that men are more prone than women to the effects of alcohol, and this could be due to the fact that alcohol consumption is higher among men than women in Norway, ${ }^{18}$ and they also suggest that women are more vulnerable to the adverse effects of smoking. Our subcohort results should be interpreted caution due to the fact that it included very few cases and any conclusions drawn need to be replicated in a larger sample size and with more detailed information on alcohol consumption. We also lacked information on tumor staging and molecular data.

Our findings are in agreement with two recent metaanalyses ${ }^{19,20}$ that reported a strong association between cigarette smoking and risk of CRC mortality. As in our study, these meta-analyses also reported a higher CRC mortality risk for current smokers than for former smokers. Our risk estimates for colon and rectal cancer mortality were also higher among current smokers than in former smokers; these results are in accordance with a study reported by Botteri et al. ${ }^{19}$ The risk of dying from proximal colon cancer was higher among women in our cohort, and this could be due to the fact that women in our study were at increased risk for proximal colon cancer compared with men. ${ }^{12}$ The observed higher site-specific increased mortality risk could be a reflection of site-specific CRC risk in our cohort.

Previous studies that included both males and females by different smoking status have shown significantly increased risk estimates for CRC mortality among both current and former smokers ${ }^{21,22}$ and among current smokers alone. ${ }^{23}$ 
Table 4 Multivariate ${ }^{a}$ adjusted HR estimates for colorectal cancer mortality by subsite and location with $95 \%$ Cls among men $(n=299,376)$ according to various measures of smoking exposure at enrollment, compared with never smokers

\begin{tabular}{|c|c|c|c|c|c|c|c|c|c|c|c|c|}
\hline & \multicolumn{3}{|c|}{ Colon cancer deaths } & \multicolumn{3}{|c|}{$\begin{array}{l}\text { Proximal colon } \\
\text { cancer deaths }\end{array}$} & \multicolumn{3}{|c|}{$\begin{array}{l}\text { Distal colon } \\
\text { cancer deaths }\end{array}$} & \multicolumn{3}{|c|}{ Rectal cancer deaths } \\
\hline & $n=922$ & HR & $95 \% \mathrm{Cl}$ & $n=416$ & HR & $95 \% \mathrm{Cl}$ & $n=320$ & HR & $95 \% \mathrm{Cl}$ & $n=485$ & HR & $95 \% \mathrm{Cl}$ \\
\hline \multicolumn{13}{|c|}{ Smoking status } \\
\hline Never & 215 & 1.00 & Ref & 103 & 1.00 & Ref & 77 & 1.00 & & 92 & 1.00 & Ref \\
\hline Former & 311 & 1.13 & $0.95-1.35$ & $|3|$ & 0.99 & $0.76-1.28$ & 123 & 1.29 & $0.97-1.73$ & $|5|$ & 1.33 & $1.02-1.73$ \\
\hline Current & 396 & 1.16 & $0.98-1.37$ & 182 & 1.08 & $0.84-1.38$ & 120 & 1.03 & $0.77-1.38$ & 242 & 1.52 & $1.19-1.94$ \\
\hline$P$-trend ${ }^{\mathrm{b}}$ & & & 0.09 & & & 0.50 & & & 0.99 & & & $<0.05$ \\
\hline Ever & 707 & 1.15 & $0.98-1.34$ & 313 & 1.04 & $0.83-1.30$ & 243 & 1.14 & $0.88-1.48$ & 393 & 1.43 & $1.14-1.81$ \\
\hline \multicolumn{13}{|c|}{ Ever smokers ${ }^{c}$} \\
\hline \multicolumn{13}{|c|}{ Age at smoking initiation (years) } \\
\hline$\geq 25$ & 83 & 1.09 & $0.84-1.41$ & 36 & 0.98 & $0.67-1.45$ & 30 & 1.16 & $0.76-1.79$ & 54 & 1.62 & $1.15-2.27$ \\
\hline $20-24$ & 132 & 1.14 & $0.92-1.42$ & 55 & 0.98 & $0.70-1.37$ & 42 & 1.04 & $0.7 I-1.52$ & 67 & 1.27 & $0.92-1.74$ \\
\hline$\leq 19$ & 255 & 1.21 & $1.00-1.46$ & 125 & 1.24 & $0.95-1.62$ & 76 & 1.01 & $0.73-1.40$ & 132 & 1.37 & $1.04-1.80$ \\
\hline$P$-trend ${ }^{b}$ & & & 0.38 & & & 0.818 & & & 0.517 & & & $<0.05$ \\
\hline \multicolumn{13}{|c|}{ Cigarettes per day (n) } \\
\hline $1-9$ & 158 & 1.05 & $0.85-1.29$ & 70 & 0.94 & $0.69-1.28$ & 60 & 1.18 & $0.84-1.67$ & 91 & 1.37 & $1.02-1.84$ \\
\hline $10-19$ & 336 & 1.18 & $0.99-1.40$ & $15 \mid$ & 1.08 & $0.84-1.40$ & 102 & 1.04 & $0.77-1.40$ & 189 & 1.47 & $1.14-1.89$ \\
\hline$\geq 20$ & 181 & 1.23 & $1.0 \mathrm{I}-1.50$ & 76 & 1.09 & $0.8 \mathrm{I}-\mathrm{I} .47$ & 69 & 1.31 & $0.94-1.82$ & 93 & 1.45 & $1.08-1.94$ \\
\hline$P$-trend ${ }^{\mathrm{b}}$ & & & $<0.05$ & & & 0.416 & & & 0.237 & & & $<0.05$ \\
\hline \multicolumn{13}{|c|}{ Years of smoking (n) } \\
\hline $1-19$ & 195 & 1.05 & $0.86-1.27$ & 89 & 0.99 & $0.74-1.31$ & 74 & 1.13 & $0.82-1.56$ & 112 & 1.31 & $1.00-1.74$ \\
\hline $20-29$ & 285 & 1.13 & $0.95-1.36$ & 117 & 0.95 & $0.73-1.25$ & 104 & 1.21 & $0.89-1.63$ & 163 & 1.41 & $1.09-1.83$ \\
\hline$\geq 30$ & 213 & 1.29 & $1.06-1.59$ & 101 & 1.27 & $0.94-1.7 \mid$ & 62 & 1.08 & $0.75-1.54$ & 108 & 1.66 & $1.23-2.24$ \\
\hline$P$-trend ${ }^{b}$ & & & $<0.05$ & & & 0.261 & & & 0.454 & & & $<0.05$ \\
\hline \multicolumn{13}{|c|}{ Pack-years of smoking $(n)$} \\
\hline $0-9$ & 194 & 1.06 & $0.87-1.29$ & 94 & 1.05 & $0.79-1.40$ & 74 & 1.16 & $0.84-1.60$ & 111 & 1.33 & $1.01-1.77$ \\
\hline $10-19$ & 235 & 1.10 & $0.91-1.33$ & 94 & 0.90 & $0.68-1.19$ & 77 & 1.05 & $0.76-1.44$ & 136 & 1.40 & $1.07-1.83$ \\
\hline$\geq 20$ & 244 & 1.33 & $1.10-1.6 \mathrm{I}$ & 109 & 1.23 & $0.93-1.63$ & 80 & 1.26 & $0.91-1.74$ & 124 & 1.59 & $1.21-2.10$ \\
\hline$P$-trend ${ }^{b}$ & & & $<0.05$ & & & 0.298 & & & 0.255 & & & $<0.05$ \\
\hline
\end{tabular}

Notes: aAdjusted for age, body mass index, level of physical activity at enrollment, and duration of education; 'bnever smokers included in the model; 'total numbers of ever smokers do not equal the total numbers in different smoking exposures due to missing data in different smoking exposure groups; ${ }^{\mathrm{d}}$ pack-years were calculated as number of cigarettes smoked per day, divided by 20 and multiplied by the number of years of smoking.

Abbreviations: $\mathrm{Cl}$, confidence interval; HR, hazards ratio; Ref, never smokers group.

Further, two of these studies also reported an association between smoking and risk of CRC mortality by sex and showed a significantly increased risk of CRC mortality both for former and current smokers ${ }^{21}$ and for current smokers alone, ${ }^{23}$ among both males and females. Few studies examining the association of smoking and risk of CRC mortality among men by subsite found a significantly increased risk of both colon and rectal cancer mortality, ${ }^{24}$ while other studies found in significant increased risk of colon and rectal cancer mortality ${ }^{25}$ and only risk of colon cancer mortality ${ }^{26}$ among current and former smokers. Similarly, a study done only among women showed a significantly increased risk of CRC mortality among both former and current smokers. ${ }^{27}$ These studies did not report results by ever smoking status.

Smoking-related risk estimates for CRC mortality were reported to be higher than incidence risk estimates, especially among current smokers. ${ }^{19}$ One possible explanation could be the probability of CRC diagnosis at advanced stages among current smokers. ${ }^{28-30}$ Increased mortality could also be due to possible differences in health behavior between smokers and nonsmokers, because smokers may be less likely to receive preventive and curative care and may have a higher incidence of comorbid conditions such as cardiovascular diseases. ${ }^{20}$ The higher risk of CRC mortality among current smokers could be due to biological factors, potential confounders, or a combination of these, as reported by Liang et $\mathrm{al},{ }^{20}$ or to a poorer response by current smokers to cancer treatment. ${ }^{31}$ Smoking has been shown to increase mortality among patients with operable CRC..$^{32} \mathrm{~A}$ recent study done by Gram et al also reported the pronounced risk of mortality from cancer, cardiovascular diseases, and respiratory diseases in current smokers compared with former smokers among middle-aged Norwegian women. ${ }^{15}$ The prevention, diagnosis, and treatment of CRC in recent years have improved in many aspects. More attention to early diagnosis and breakthroughs in treatment have contributed to decreased mortality and 
Table 5 Multivariate ${ }^{\text {a }}$ adjusted HR estimates for colorectal cancer mortality by subsite and location with $95 \%$ Cls among women $(n=302,866)$ according to various measures of smoking exposure at enrollment, compared with never smokers

\begin{tabular}{|c|c|c|c|c|c|c|c|c|c|c|c|c|}
\hline & \multicolumn{3}{|c|}{ Colon cancer deaths } & \multicolumn{3}{|c|}{$\begin{array}{l}\text { Proximal colon cancer } \\
\text { deaths }\end{array}$} & \multicolumn{3}{|c|}{$\begin{array}{l}\text { Distal colon cancer } \\
\text { deaths }\end{array}$} & \multicolumn{3}{|c|}{ Rectal cancer deaths } \\
\hline & $n=685$ & HR & $95 \% \mathrm{Cl}$ & $n=356$ & HR & $95 \% \mathrm{Cl}$ & $\mathbf{n}=\mathbf{2 2 0}$ & HR & $95 \% \mathrm{Cl}$ & $n=241$ & HR & $95 \% \mathrm{Cl}$ \\
\hline \multicolumn{13}{|c|}{ Smoking status } \\
\hline Never & 307 & 1.00 & Ref & 146 & 1.00 & Ref & 106 & 1.00 & Ref & 110 & 1.00 & Ref \\
\hline Former & 132 & 1.21 & $0.98-1.49$ & 74 & 1.46 & $1.10-1.94$ & 41 & 1.03 & $0.72-1.49$ & 30 & 0.74 & $0.50-1.11$ \\
\hline Current & 246 & 1.30 & $1.09-1.55$ & 136 & 1.52 & $1.19-1.95$ & 73 & 1.04 & $0.76-1.42$ & 101 & 1.30 & $1.00-1.74$ \\
\hline$P$-trend ${ }^{b}$ & & & $<0.05$ & & & $<0.05$ & & & 0.78 & & & 0.10 \\
\hline Ever & 378 & 1.26 & $1.08-1.48$ & 210 & 1.49 & $1.20-1.87$ & 114 & 1.04 & $0.79-1.36$ & 131 & 1.09 & $0.84-1.42$ \\
\hline \multicolumn{13}{|c|}{ Ever smokers ${ }^{c}$} \\
\hline \multicolumn{13}{|c|}{ Age at smoking initiation (years) } \\
\hline$\geq 25$ & 95 & 1.28 & $1.02-1.6 \mathrm{I}$ & 49 & 1.35 & $0.97-1.87$ & 33 & 1.33 & $0.90-1.98$ & 33 & 1.16 & $0.78-1.72$ \\
\hline $20-24$ & 95 & 1.32 & $1.04-1.67$ & 49 & 1.47 & $1.05-2.05$ & 33 & 1.20 & $0.80-1.79$ & 38 & 1.30 & $0.89-1.90$ \\
\hline$\leq 19$ & 94 & 1.22 & $0.95-1.56$ & 57 & 1.63 & $1.17-2.26$ & 21 & 0.67 & $0.4 I-1.09$ & 37 & 1.15 & $0.77-1.7 \mid$ \\
\hline$P$-trend ${ }^{b}$ & & & $<0.05$ & & & $<0.05$ & & & 0.131 & & & 0.24 \\
\hline \multicolumn{13}{|c|}{ Cigarettes per day (n) } \\
\hline $1-9$ & 140 & 1.16 & $0.95-1.42$ & 76 & 1.32 & $0.99-1.75$ & 44 & 1.04 & $0.73-1.48$ & 44 & 0.94 & $0.66-1.33$ \\
\hline $10-19$ & 185 & 1.32 & $1.09-1.59$ & 99 & 1.52 & $1.16-1.99$ & 60 & 1.14 & $0.8 \mathrm{I}-1.58$ & 73 & 1.29 & $0.94-1.75$ \\
\hline$\geq 20$ & 48 & 1.40 & $1.02-1.91$ & 31 & 1.99 & $1.33-2.96$ & 10 & 0.74 & $0.38-1.43$ & 14 & 1.02 & $0.58-1.79$ \\
\hline$P$-trend ${ }^{b}$ & & & $<0.05$ & & & $<0.0001$ & & & 0.968 & & & 0.257 \\
\hline \multicolumn{13}{|c|}{ Years of smoking (n) } \\
\hline $1-19$ & 175 & 1.29 & $1.06-1.57$ & 94 & $\mid .51$ & $1.15-1.98$ & 56 & 1.11 & $0.79-1.55$ & 54 & 1.00 & $0.71-1.40$ \\
\hline $20-29$ & 155 & 1.28 & $1.04-1.57$ & 88 & 1.57 & I.18-2.07 & 48 & 1.06 & $0.74-1.52$ & 62 & 1.23 & $0.89-1.7 \mid$ \\
\hline$\geq 30$ & 41 & 1.10 & $0.78-1.54$ & 24 & 1.29 & $0.82-2.02$ & 9 & 0.74 & $0.40-1.5 \mid$ & 15 & 1.13 & $0.64-1.00$ \\
\hline$P$-trend ${ }^{b}$ & & & $<0.05$ & & & $<0.05$ & & & 0.848 & & & 0.262 \\
\hline \multicolumn{13}{|c|}{ Pack-years of smoking ${ }^{d}(n)$} \\
\hline $0-9$ & 178 & 1.16 & $0.96-1.40$ & 97 & 1.33 & $1.03-1.74$ & 57 & 1.02 & $0.73-1.42$ & 56 & 0.93 & $0.67-1.29$ \\
\hline $10-19$ & 140 & 1.40 & I.I4-I.73 & 72 & 1.53 & I.14-2.05 & 48 & 1.29 & $0.91-1.85$ & 53 & 1.30 & $0.93-1.83$ \\
\hline$\geq 20$ & 51 & 1.28 & $0.95-1.73$ & 35 & 1.86 & $|.28-2.7|$ & 8 & 0.55 & $0.26-1.12$ & 22 & 1.42 & $0.89-2.25$ \\
\hline$P$-trend ${ }^{b}$ & & & $<0.05$ & & & $<0.0001$ & & & 0.883 & & & 0.069 \\
\hline
\end{tabular}

Notes: aAdjusted for age, body mass index, level of physical activity at enrollment, and duration of education; 'bever smokers included in the model; 'total numbers of ever smokers do not equal the total numbers in different smoking exposures due to missing data in different smoking exposure groups; dpack-years were calculated as number of cigarettes smoked per day, divided by 20 and multiplied by the number of years of smoking.

Abbreviations: $\mathrm{Cl}$, confidence interval; $\mathrm{HR}$, hazards ratio; Ref, never smokers group.

increased survival compared with earlier decades. Our finding of decreased mortality risk estimations in the recent surveys, such as the CONOR study, compared with earlier ones, such as the Norwegian Counties Study, further supports this notion.

\section{Conclusion}

Smoking is associated with increased CRC mortality in both males and females. The risk of rectal and proximal colon cancer mortality, respectively, was most pronounced in male and female smokers.

\section{Acknowledgments}

This research was supported by grants from the Norwegian Cancer Society as a $\mathrm{PhD}$ project for the main author (PK 2009-0430, PK01-2009-0341). The authors acknowledge the services of CONOR, the contributing research centers delivering data to CONOR, and all the study participants. The authors also thank Professor Anders Engeland, Randi
Selmer (senior researcher), Knut Hansen (data manager), and Ilene Brill (data analyst) for helping us to merge the different surveys and prepare the master data, file, and Tonje Braaten for her assistance with the statistical analysis.

\section{Disclosure}

The authors report no conflicts of interest in this work.

\section{References}

1. Ferlay J, Shin HR, Bray F, Forman D, Mathers C, Parkin DM. Estimates of worldwide burden of cancer in 2008: GLOBOCAN 2008. Int J Cancer. 2010;127(12):2893-2917.

2. Ferlay J, Parkin DM, Steliarova-Foucher E. Estimates of cancer incidence and mortality in Europe in 2008. Eur J Cancer. 2010;46(4): 765-781.

3. Cancer Registry of Norway. Cancer in Norway 2011-Cancer Incidence, Mortality, Survival and Prevalence in Norway. Oslo, Norway: Cancer Registry of Norway; 2013.

4. US Dept of Health and Human Services. Women and Smoking: A Report of the Surgeon General. Rockville, MD, USA: US Dept of Health and Human Services, Public Health Service, Office of the Surgeon General; 2001. 
5. World Health Organization. Tobacco. Geneva, Switzerland: The World Health Organization; 2013.

6. International Agency for Research on Cancer. Monographs on the Evaluation of Carcinogenic Risks to Humans. Personal Habits and Indoor Combustions. A Review of Human Carcinogens. Lyon, France: IARC Press; 2012

7. Haggar FA, Boushey RP. Colorectal cancer epidemiology: incidence, mortality, survival, and risk factors. Clin Colon Rectal Surg. 2009;22(4): 191-197.

8. Zisman AL, Nickolov A, Brand RE, Gorchow A, Roy HK. Associations between the age at diagnosis and location of colorectal cancer and the use of alcohol and tobacco: implications for screening. Arch Intern Med. 2006;166(6):629-634.

9. Helleve A, Weisæth A, Lindbak R. [Figures about Tobacco 1973-2009]. Oslo, Norway: Norwegian Directorate of Health; 2010. . Available from http://helsedirektoratet.no/folkehelse/tobakk/tall-og-undersokelser/ Documents/Tal-om-tobakk-1973-2009.pdf. Accessed October 9, 2013. Norwegian.

10. Lund M, Lindback R. Norwegian Tobacco Statistics 1973-2006. SIRUSWritings 3/2007. 2007. Available from http://www.sirus.no/filestore/ Import_vedlegg/sirusskrifter3.07.pdf, Accessed October 9, 2013.

11. Norway's public reports. [Tobacco industry liability]. Oslo, Norway: Statens forvaltningstjeneste, Informasjonsforvaltning. NOU; 2000.

12. Parajuli R, Bjerkaas E, Tverdal A, et al. The increased risk of colon cancer due to cigarette smoking may be greater in women than men. Cancer Epidemiol Biomarkers Prev. 2013;22(5):862-871.

13. Bjerkaas E, Parajuli R, Weiderpass E, et al. Smoking duration before first childbirth: an emerging risk factor for breast cancer? Results from 302,865 Norwegian women. Cancer Causes Control. 2013;24(7):1347-1356.

14. Larsen IK, Smastuen M, Johannesen TB, et al. Data quality at the Cancer Registry of Norway: an overview of comparability, completeness, validity and timeliness. Eur J Cancer. 2009;45(7):1218-1231.

15. Gram IT, Sandin S, Braaten T, Lund E, Weiderpass E. The hazards of death by smoking in middle-aged women. Eur J Epidemiol. 2013;28(10):799-806.

16. Thun M, Peto R, Boreham J, Lopez AD. Stages of the cigarette epidemic on entering its second century. Tob Control. 2012;21(2):96-101.

17. Baan R, Straif K, Grosse Y, et al. Carcinogenicity of alcoholic beverages. Lancet Oncol. 2007;8(4):292-293.

18. Strand BH, Steiro A. [Alcohol consumption, income and education in Norway, 1993-2000]. Tidsskr Nor Laegeforen. 2003;123(20): 2849-2853. Norwegian.

19. Botteri E, Iodice S, Bagnardi V, Raimondi S, Lowenfels AB, Maisonneuve P. Smoking and colorectal cancer: a meta-analysis. JAMA. 2008;300(23):2765-2778.

20. Liang PS, Chen TY, Giovannucci E. Cigarette smoking and colorectal cancer incidence and mortality: systematic review and meta-analysis. Int J Cancer. 2009;124(10):2406-2415.

21. Chao A, Thun MJ, Jacobs EJ, Henley SJ, Rodriguez C, Calle EE. Cigarette smoking and colorectal cancer mortality in the Cancer Prevention Study II. J Natl Cancer Inst. 2000;92(23):1888-1896.

22. Huxley R. The role of lifestyle risk factors on mortality from colorectal cancer in populations of the Asia-Pacific region. Asian Pac J Cancer Prev. 2007;8(2):191-198.

23. Colangelo LA, Gapstur SM, Gann PH, Dyer AR. Cigarette smoking and colorectal carcinoma mortality in a cohort with long-term follow-up. Cancer. 2004;100(2):288-293.

\section{Clinical Epidemiology}

\section{Publish your work in this journal}

Clinical Epidemiology is an international, peer-reviewed, open access journal focusing on disease and drug epidemiology, identification of risk factors and screening procedures to develop optimal preventative initiatives and programs. Specific topics include: diagnosis, prognosis, treatment, screening, prevention, risk factor modification, systematic
24. Heineman EF, Zahm SH, McLaughlin JK, Vaught JB. Increased risk of colorectal cancer among smokers: results of a 26-year follow-up of US veterans and a review. Int J Cancer. 1994;59(6):728-738.

25. Batty GD, Kivimaki M, Gray L, Smith GD, Marmot MG, Shipley MJ. Cigarette smoking and site-specific cancer mortality: testing uncertain associations using extended follow-up of the original Whitehall study. Ann Oncol. 2008;19(5):996-1002.

26. Hsing AW, McLaughlin JK, Chow WH, et al. Risk factors for colorectal cancer in a prospective study among US white men. Int J Cancer. 1998;77(4):549-553.

27. Kenfield SA, Stampfer MJ, Rosner BA, Colditz GA. Smoking and smoking cessation in relation to mortality in women. JAMA. 2008;299(17):2037-2047.

28. Campbell RJ, Ferrante JM, Gonzalez EC, Roetzheim RG, Pal N, Herold A. Predictors of advanced stage colorectal cancer diagnosis: results of a population-based study. Cancer Detect Prev. 2001;25(5):430-438.

29. Daniell HW. More advanced colonic cancer among smokers. Cancer. 1986;58(3):784-787.

30. Longnecker MP, Clapp RW, Sheahan K. Associations between smoking status and stage of colorectal cancer at diagnosis in Massachusetts between 1982 and 1987. Cancer. 1989;64(6):1372-1374.

31. Mai SK, Welzel G, Haegele V, Wenz F. The influence of smoking and other risk factors on the outcome after radiochemotherapy for anal cancer. Radiat Oncol. 2007;2:30.

32. Munro AJ, Bentley AH, Ackland C, Boyle PJ. Smoking compromises cause-specific survival in patients with operable colorectal cancer. Clin Oncol (R Coll Radiol ). 2006;18(6):436-440.

33. Leren P. The Oslo study. Cardiovascular disease in middle-aged and young Oslo men. Acta med Scand Suppl. 1975;588:1-38.

34. Lund HL. Metabolic syndrome predicts prostate cancer in a cohort of middle-aged Norwegian men followed for 27 years. Am J Epidermiol. 2006;164(8):769-774.

35. Solberg LA. Stenoses in the coronary arteries. Relation to atherosclerotic lesions, coronary heart disease, and risk factors. The Oslo Study. Lab Invest. 1985;53(6):648-655.

36. StocksT, Borena W, Strohmaier S etal. Cohort profile: the metabolic syndrome and cancer project (Me-Can). Int J Epidemiol. 2010;39(3):660-667.

37. Bjartveit $\mathrm{K}$. The cardiovascular disease study in Norwegian counties. Background and organization. Acta med Scand Suppl. 1979; 634:1-70.

38. Tverdal A. Serum triglycerides as an independent risk factor for death from coronary heart disease in middle-aged Norwegian men. 1989.

39. Tverdal A, Bjartveit $\mathrm{K}$. Health consequences of reduced daily cigarette consumption. Tob Control. 2006;15(6):472-480.

40. Aires N. The validity of self-reported leisure time physical activity, and its relationship to serum cholesterol, blood pressure and body mass index. A population based study of 332,182 male and female aged 40-42 years. Eur J Epidemiol. 2003;18(6);479-485.

41. Bjartveit K, Stensvold I, Lund-Larsen PG, Gjervig T, Kruger O, Urdal P. [Cardiovascular screenings in Norwegian counties. Background and implementation. Status of risk pattern during the period 1986-90 among persons aged 40-42 years in 14 counties]. Tidsskr Nor Laegeforen. 1991;111(17):2063-2067. Norwegian.

42. Aamodt G, Sogaard AJ, Naess O, Beckstrom AC, Samuelsen SO. CONORdatabasen - et lite stykke Norge [The CONOR database--a little piece of Norway]. Tidsskr Nor Laegeforen. 2010;130(3):264-265. Norwegian.

43. Naess O, Sogaard AJ, Arnesen E et al. Cohort profile: cohort of Norway (CONOR). Int J Epidemiol. 2008;37(3):481-485.

\section{Dovepress}

reviews, risk \& safety of medical interventions, epidemiology \& biostatical methods, evaluation of guidelines, translational medicine, health policies \& economic evaluations. The manuscript management system is completely online and includes a very quick and fair peer-review system, which is all easy to use. 